\title{
Productivity Analysis of Punjab State Warehousing Corporation
}

\author{
Rashpaljeet $\operatorname{Kaur}^{1}$ Dr. Rajinder Kaur ${ }^{2}$ \\ ${ }^{1}$ (Research Scholar, Department of Commerce, Punjabi University, Patiala, India) \\ ${ }^{2}$ (Professor, Department of Commerce, Punjabi University, Patiala, India)
}

\begin{abstract}
This paper examines the productivity analysis of Punjab State Warehousing Corporation (PSWC). The data from 2000-01 to 2012-13 has been collected from secondary sources for the study. The data has been analyzed with the help of mean, compound growth rate and productivity ratios. The productivity analysis of PSWC has been studied on the basis of warehouse productivity and employee productivity. The reveals that the PSWC earned more income than expenses per warehouse and per employee in 2000-01, 2002-03, 2003-04, 2004-05 and 2005-06 which showed that each warehouse and employee of the Corporation was efficient in controlling its expenses but after 2005-06, income per warehouse and per employee was less than expenses per warehouse and per employee which indicated the inefficiency of the Corporation's warehouses and employees in controlling the expenses.
\end{abstract}

Key words: - Warehouse, Employee, Productivity, Metric Tonne, Storage capacity.

\section{Introduction}

Productivity expresses the efficiency with which output is produced by the resources utilized. Productivity means the output production per unit of input. It is usually measured as a ratio of output to inputs. Productivity could be considered as a measure of how organizations are using the resources effectively to generate useful output. Higher productivity means accomplishing more with the same amount of resources or achieving higher output with the same input. Raising productivity means making more effective use of resources.

Productivity analysis is important for productivity improvement. Therefore, the productivity analysis forms a part of performance evaluation exercise of an entity. It is an effective tool for decision making at all economic levels. The term 'productivity analysis' includes both 'analysis' and 'interpretation'. The term analysis is used to mean the generalization of data given in financial statements by systematic arrangement and classification of data and 'interpretation' means explaining the meaning and significance of the data so simplified. However, both analysis and interpretation are interlinked and complimentary to each other.

In this paper an attempt has been made to study the productivity analysis of Punjab State Warehousing Corporation (PSWC). Punjab State Warehousing Corporation was originally established on 2.01.1958 for the purpose of warehousing of agricultural produce and other notified commodities by the State Government complying with the provisions of Agricultural Produce (Development and Warehousing) Corporations Act, 1956 which was subsequently repealed and replaced by the Warehousing Corporations Act, 1962. PSWC offers entire warehousing services to the agriculturists of Punjab. These prompt services have been made possible because of vast network offices at almost entire nook and corner of the state of Punjab.

\section{Objectives}

The objectives of the present study are given below:

- To study the productivity of the Punjab State Warehousing Corporation by studying warehouse productivity and employee productivity.

- To give the suggestions on the basis of findings of the study.

\section{Research Methodology}

The data for the period of 2000-01 to 2012-13 has been collected from secondary sources. The data has been collected from annual reports of Punjab State Warehousing Corporation and analyzed by using mean and compound growth rate. The productivity analysis of PSWC is measured by using productivity ratios like average storage capacity per warehouse, average utilization of storage capacity per warehouse, total income per warehouse, total expenses per warehouse, net profit/loss per warehouse, procurement of paddy per employee, procurement of wheat per employee, total income per employee, total expenses per employee, net profit/loss per employee. The data on procurement of paddy per employee and procurement of wheat per employee during 2012-13 is not available. 


\section{Productivity Analysis} ratios:

The productivity analysis of PSWC has been studied on the basis of following variables of productivity

\subsection{WAREHOUSE PRODUCTIVITY}

The PSWC provides warehousing facilities for storing food grains, fertilizers and other non-food grain commodities in Punjab. The main aim of PSWC with the network of 114 warehouses spread across the entire state of Punjab is scientific warehousing which involves protecting the agricultural produce from seasonal and natural hazards, pests, rats and moisture by using the most modern techniques and taking precautionary measures like spraying pesticides and insecticides. The storage of food grains and other commodities is done in the own constructed godowns of PSWC or hired godowns. The warehouse productivity during the period 200001 to 2012-13 has been determined on the basis of selected parameters like:

\subsubsection{Average Storage Capacity per Warehouse}

The average storage capacity per warehouse represents the ratio of total average storage capacity in metric tonne by the total number of warehouses. The table 1 shows that the average storage capacity per warehouse has shown fluctuating trend during the study period. It reveals that the total average storage capacity per warehouse increased from 33954.54 MT in 2000-01 to 51517.54 MT in 2012-13 registering a compound growth rate of 3.26 per cent and mean value was 51181.07 MT over the study period. The higher value of average storage capacity per warehouse was 64042.73 MT in 2002-03 which indicated the higher storage capacity available in each warehouse of the PSWC as compared to other years of the study period.

TABLE 1- AVERAGE STORAGE CAPACITY PER WAREHOUSE

\begin{tabular}{|c|c|}
\hline Year & $\begin{array}{c}\text { (In Metric Tonne) } \\
\text { Avtorage capacity per } \\
\text { warehouse }\end{array}$ \\
\hline $2000-01$ & 33954.54 \\
\hline $2001-02$ & 52782.61 \\
\hline $2002-03$ & 64042.73 \\
\hline $2003-04$ & 58991.38 \\
\hline $2004-05$ & 52922.41 \\
\hline $2005-06$ & 51551.72 \\
\hline $2006-07$ & 49617.39 \\
\hline $2007-08$ & 48298.24 \\
\hline $2008-09$ & 45894.73 \\
\hline $2009-10$ & 50368.42 \\
\hline $2010-11$ & 51008.77 \\
\hline $2011-12$ & 54403.51 \\
\hline $2012-13$ & 51517.54 \\
\hline MEAN & $\mathbf{5 1 1 8 1 . 0 7}$ \\
\hline CGR & $\mathbf{3 . 2 6 \%}$ \\
\hline (Source: Calculated from the record maintained by Statistical Officer of PSWC for the period 2000-01 to 2012-13)
\end{tabular}

\subsubsection{Average Utilization of Storage Capacity per Warehouse}

The proper utilization of space in the warehouses is very important for the PSWC. The storage capacity of the warehouses is utilized for storing food grains, fertilizers and other non-food grain commodities. The average utilization of storage capacity per warehouse has been calculated by dividing total average utilization of storage capacity during the period of study by the number of warehouses. It is observed from the table 2 that the total average storage capacity utilization per warehouse was showing a fluctuating trend during the study period. The mean value of average utilization of storage capacity per warehouse was $43324.50 \mathrm{MT}$ and registered a compound growth rate of 2.64 per cent over the study period. By comparing the table 1 and table 2, it has been found that the average utilization per warehouse was less than the average storage capacity per warehouse in all the years because the average storage capacity of the warehouses was not fully utilized by the depositors over the study period. 


\section{TABLE 2-AVERAGE UTILIZATION OF STORAGE CAPACITY PER WAREHOUSE}

(In Metric Tonne)

\begin{tabular}{|c|c|}
\hline Year & $\begin{array}{c}\text { Avg. utilization per } \\
\text { warehouse }\end{array}$ \\
\hline $2000-01$ & 33636.36 \\
\hline $2001-02$ & 50869.56 \\
\hline $2002-03$ & 57521.36 \\
\hline $2003-04$ & 48275.86 \\
\hline $2004-05$ & 41163.79 \\
\hline $2005-06$ & 35051.72 \\
\hline $2006-07$ & 35217.39 \\
\hline $2007-08$ & 35000 \\
\hline $2008-09$ & 38122.80 \\
\hline $2009-10$ & 42105.26 \\
\hline $2010-11$ & 46771.93 \\
\hline $2011-12$ & 52271.93 \\
\hline $2012-13$ & 47210.53 \\
\hline MEAN & $\mathbf{4 3 3 2 4 . 5 0}$ \\
\hline CGR & $\mathbf{2 . 6 4 \%}$ \\
\hline
\end{tabular}

(Source: Calculated from the record maintained by Statistical Officer of PSWC for the period 2000-01 to 2012-13)

\subsubsection{Total Income per Warehouse}

The total income per warehouse shows the proportionate share of total income earned per warehouse. The total income of the Corporation mainly increased with the increase in the income from warehousing charges because income from warehousing charges formed the major portion of the total income. It is clear from the table 3 that total income per warehouse increased from Rs. 78.08 lac in 2000-01 to Rs.320.17 lac in 2012-13 registering a compound growth rate of 11.47 per cent and the mean value was Rs. 192.17 lac during the study period. The total income per warehouse was higher (Rs.320.17 lac) in 2012-13 due to more income generated by each warehouse of the PSWC in form of warehousing charges as compared to other years of study period which represented higher warehouse productivity.

\section{TABLE 3-TOTAL INCOME PER WAREHOUSE}

\begin{tabular}{|c|c|}
\hline Year & $\begin{array}{c}\text { Total income per } \\
\text { warehouse }\end{array}$ \\
\hline $2000-01$ & 78.08 \\
\hline $2001-02$ & 139.66 \\
\hline $2002-03$ & 233.98 \\
\hline $2003-04$ & 187.47 \\
\hline $2004-05$ & 156.70 \\
\hline $2005-06$ & 153.85 \\
\hline $2006-07$ & 154.42 \\
\hline $2007-08$ & 166.09 \\
\hline $2008-09$ & 183.01 \\
\hline $2009-10$ & 146.51 \\
\hline $2010-11$ & 276.10 \\
\hline $2011-12$ & 302.30 \\
\hline $2012-13$ & 320.17 \\
\hline MEAN & $\mathbf{1 9 2 . 1 7}$ \\
\hline CGR & $\mathbf{1 1 . 4 7 \%}$ \\
\hline
\end{tabular}

(Source: Calculated from annual reports and the record maintained by Statistical Officer of PSWC for the period 2000-01 to 2012-13)

\subsubsection{Total Expenses per Warehouse}

The total expenses per warehouse have been calculated by dividing the total expenses by number of warehouses during the period of study. The table 4 reveals that the ratio of total expenses per warehouse ranged 
in between Rs.75.90 lac and Rs.555.13 lac during the study period. The lowest value of total expenses per warehouse during 2000-01 which was satisfactory but higher value of total expenses per warehouse during 2012-13 was not satisfactory because it would have negative impact on the productivity of each warehouse of the Corporation. The total expenses per warehouse increased from Rs.75.90 lac in 2000-01 to Rs.555.13 lac in 2012-13 registering a compound growth rate of 16.54 per cent and the mean value of Rs.244.67 lac during the period of study. It is observed by comparing the tables 3 and 4 that the Corporation earned more income than expenses per warehouse in 2000-01, 2002-03, 2003-04, 2004-05 and 2005-06 which shows that each warehouse of the Corporation was efficient in controlling its expenses but after 2005-06, income per warehouse was less than expenses per warehouse which indicated the inefficiency of the Corporation's warehouses in controlling the expenses.

TABLE 4-TOTAL EXPENSES PER WAREHOUSE

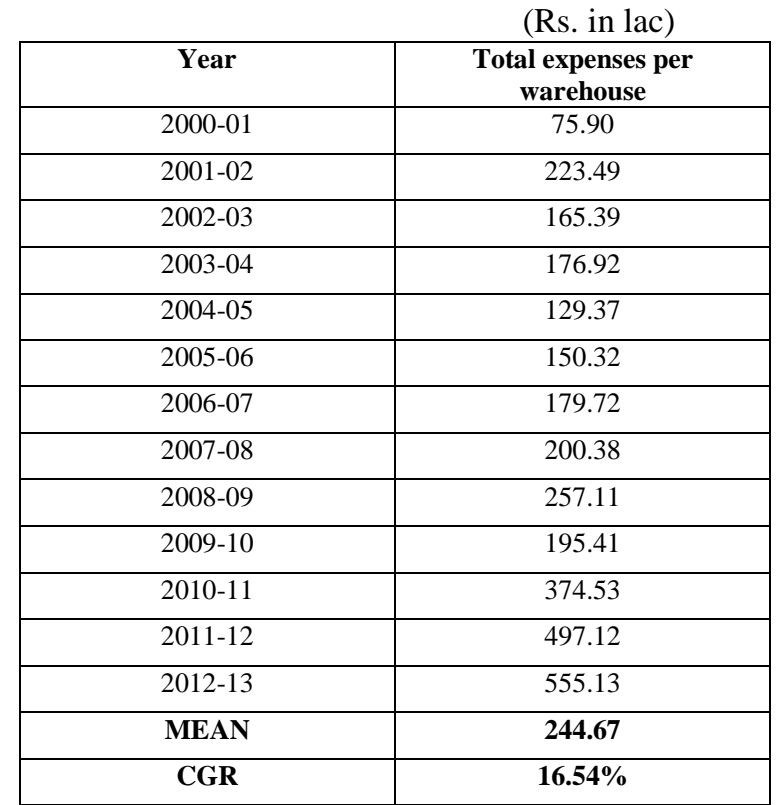

(Source: Calculated from annual reports and the record maintained by Statistical Officer of PSWC for the period 2000-01 to 2012-13)

\subsubsection{Net Profit/Loss per Warehouse}

Net profit/loss per warehouse is obtained by dividing the net profit/loss during the period of study by number of warehouse. The table 5 shows that the net profit per warehouse ratio was positive only in (Rs.1.46 lac which was low) 2000-01 and (Rs.77.36 lac) 2002-03 but in remaining years of the study period, it was negative. The figures in the table indicate that the Corporation had generated profits during the years 2000-01 and 200203 but incurred losses in the remaining years. The PSWC has shown the net losses may be due to rise in the expenses, under utilization of warehousing facilities and deficit from paddy \& wheat procurement. It registered the negative compound growth rate and negative mean value during the study period. The negative ratio values indicated the lower warehouse productivity.

TABLE 5- NET PROFIT/LOSS PER WAREHOUSE

\begin{tabular}{|c|c|}
\hline Year & $\begin{array}{c}\text { Net profit/loss per } \\
\text { warehouse }\end{array}$ \\
\hline $2000-01$ & 1.46 \\
\hline 2001-02 & -100.18 \\
\hline 2002-03 & 77.36 \\
\hline 2003-04 & -16.18 \\
\hline 2004-05 & -36.62 \\
\hline $2005-06$ & -48.65 \\
\hline $2006-07$ & -67.61 \\
\hline $2007-08$ & -76.00 \\
\hline 2008-09 & -28.54 \\
\hline $2009-10$ & -49.26 \\
\hline $2010-11$ & -94.24 \\
\hline 2011-12 & -194.76 \\
\hline $2012-13$ & -243.53 \\
\hline MEAN & -67.44 \\
\hline CGR & -ive \\
\hline
\end{tabular}

(Source: Calculated from annual reports and the record maintained by Statistical Officer of PSWC for the period 2000-01 to 2012-13) 


\subsection{EMPLOYEE PRODUCTIVITY}

The principal resource of any organization is the people. An important objective of every organization is the survival and growth. The various employees of the organization put their best efforts in order to achieve these objectives. The performance of an organization and resulting productivity are directly proportional to the quantity of its human resources. In this section an attempt has been made to study whether the present work force of the PSWC is sufficient to carry out the activities or there is any need to add additional work force to the existing number for achieving higher productivity. The employee productivity during the period 2000-01 to 2012-13 has been determined on the basis of selected parameters like:

\subsubsection{Procurement of Paddy per Employee}

The work force of the PSWC procures the paddy on behalf of Govt. during the kharif season in the mandies allotted by Punjab Government. The procurement of paddy per employee represents the ratio of total paddy procured in metric tonne divided by the total number of employees. The table 6 reveals that the ratio of procurement of paddy per employee in PSWC ranged from 628.34 MT to 1129.67 MT during 2000-01 to 201112. The procurement of paddy per employee increased from 733.51 MT in 2000-01 to 801.84 MT in 2011-12 registering a compound growth rate of 0.74 per cent and mean value of 812.06 MT. During 2009-10, the value of procurement of paddy per employee was higher as compared to other years of study period which showed higher employee productivity.

\section{TABLE 6- PROCUREMENT OF PADDY PER EMPLOYEE}

(In Metric Tonne)

\begin{tabular}{|c|c|}
\hline Year & $\begin{array}{c}\text { Procurement of paddy } \\
\text { per employee }\end{array}$ \\
\hline $2000-01$ & 733.51 \\
\hline $2001-02$ & 848.05 \\
\hline $2002-03$ & 628.34 \\
\hline $2003-04$ & 634.85 \\
\hline $2004-05$ & 688.98 \\
\hline $2005-06$ & 833.33 \\
\hline $2006-07$ & 702.38 \\
\hline $2007-08$ & 837.33 \\
\hline $2008-09$ & 990.77 \\
\hline $2009-10$ & 1129.67 \\
\hline $2010-11$ & 915.69 \\
\hline $2011-12$ & 801.84 \\
\hline MEAN & $\mathbf{8 1 2 . 0 6}$ \\
\hline CGR & $\mathbf{0 . 7 4 \%}$ \\
\hline
\end{tabular}

(Source: Calculated from the record of procurement branch and the record of salary section of account branch of PSWC for the period 200001 to 2011-12)

\subsubsection{Procurement of Wheat per Employee}

The work force of the PSWC procures the wheat on behalf of Govt. during the Rabi season in the mandies allotted by Punjab Government. The procurement of wheat per employee represents the ratio of total wheat procured in metric tonne divided by the total number of employees. The table 7 reveals that the ratio of procurement of wheat per employee in PSWC has shown fluctuating trend over the study period. It was ranging from 459.52 MT to 903.07 MT during 2000-01 to 2011-12. The procurement of wheat per employee increased from 774.72 MT in 2000-01 to 790.15 MT in 2011-12 registering a compound growth rate of 0.16 per cent and mean value of 663.84 MT. During 2009-10, the procurement of wheat per employee was higher as compared to other years of study period which showed that the higher quantity of wheat procured by each employee of the Corporation during this year. It is clear from the tables 6 and 7, the quantity of paddy procured by each employee was more than the quantity of wheat procured by each employee of the Corporation from 2001-02 to 2011-12. 
TABLE 7- PROCUREMENT OF WHEAT PER EMPLOYEE

(In Metric Tonne)

\begin{tabular}{|c|c|}
\hline Year & $\begin{array}{c}\text { Procurement of wheat per } \\
\text { employee }\end{array}$ \\
\hline $2000-01$ & 774.72 \\
\hline $2001-02$ & 672.51 \\
\hline $2002-03$ & 619.41 \\
\hline $2003-04$ & 576.94 \\
\hline $2004-05$ & 601.02 \\
\hline $2005-06$ & 610.32 \\
\hline $2006-07$ & 459.52 \\
\hline $2007-08$ & 473.81 \\
\hline $2008-09$ & 792.35 \\
\hline $2009-10$ & 903.07 \\
\hline $2010-11$ & 692.31 \\
\hline $2011-12$ & 790.15 \\
\hline MEAN & $\mathbf{6 6 3 . 8 4}$ \\
\hline CGR & $\mathbf{0 . 1 6 \%}$ \\
\hline
\end{tabular}

(Source: Calculated from the record of procurement branch and the record of salary section of account branch of PSWC for the period 200001 to 2011-12)

\subsubsection{Total Income per Employee}

The total income per employee shows the proportionate share of total income earned per employee. Total income per employee has been calculated by dividing the total income earned during the period of study by number of employees. Table 8 shows that total income per employee increased from Rs. 4.71 lac in 2000-01 to Rs.22.46 lac in 2012-13 registering a compound growth rate of 12.77 per cent and the mean value was Rs. 13.22 lac during the study period. The higher value of total income per employee was Rs.22.46 lac in 2012-13 which represents the good efforts took by each employee of the Corporation for increasing the income as compared to other years of study period.

TABLE 8-TOTAL INCOME PER EMPLOYEE

\begin{tabular}{|c|c|}
\hline Year & $\begin{array}{c}\text { Total income per } \\
\text { employee }\end{array}$ \\
\hline $2000-01$ & 4.71 \\
\hline $2001-02$ & 8.81 \\
\hline $2002-03$ & 15.27 \\
\hline $2003-04$ & 11.99 \\
\hline $2004-05$ & 10.31 \\
\hline $2005-06$ & 10.47 \\
\hline $2006-07$ & 10.57 \\
\hline $2007-08$ & 11.66 \\
\hline $2008-09$ & 13.75 \\
\hline $2009-10$ & 11.16 \\
\hline $2010-11$ & 19.37 \\
\hline $2011-12$ & 21.21 \\
\hline $2012-13$ & 22.46 \\
\hline MEAN & $\mathbf{1 3 . 2 2}$ \\
\hline CGR & $\mathbf{1 2 . 7 7 \%}$ \\
\hline
\end{tabular}

(Source: Calculated from annual reports and the record of salary section of account branch of PSWC for the period 2000-01 to 2012-13)

\subsubsection{Total Expenses per Employee}

The total expenses per employee have been calculated by dividing the total expenses by number of employees during the period of study. The table 9 reveals that the ratio of total expenses per employee ranged in between Rs.4.58 lac and Rs.38.94 lac during the study period. The total expenses per employee increased from 
Rs.4.58 lac in 2000-01 to Rs.38.94 lac in 2012-13 registering a compound growth rate of 17.90 per cent and the mean value of Rs.16.93 lac during the period of study. On the whole, it is observed from the tables 8 and 9 that the income per employee was more than the expenses per employee in the years 2000-01, 2002-03, 2003-04, 2004-05 and 2005-06 which represents that the Corporation's workforce was able in earning more income than expenses in these years. On the other hand, after 2005-06, the income per employee was less than the expenses per employee which showed the inability of the employees of the Corporation in controlling expenses.

TABLE 9 -TOTAL EXPENSES PER EMPLOYEE

(Rs. in lac)

\begin{tabular}{|c|c|}
\hline Year & Total expenses per employee \\
\hline $2000-01$ & 4.58 \\
\hline $2001-02$ & 14.09 \\
\hline $2002-03$ & 10.79 \\
\hline $2003-04$ & 11.31 \\
\hline $2004-05$ & 8.51 \\
\hline $2005-06$ & 10.23 \\
\hline $2006-07$ & 12.30 \\
\hline $2007-08$ & 14.07 \\
\hline $2008-09$ & 19.32 \\
\hline $2009-10$ & 14.89 \\
\hline $2010-11$ & 26.27 \\
\hline $2011-12$ & 34.87 \\
\hline $2012-13$ & 38.94 \\
\hline MEAN & $\mathbf{1 6 . 9 3}$ \\
\hline CGR & $\mathbf{1 7 . 9 0 \%}$ \\
\hline
\end{tabular}

(Source: Calculated from annual reports and the record of salary section of account branch of PSWC for the period 2000-01 to 2012-13)

\subsubsection{Net Profit/Loss per Employee}

Net profit/loss per employee is obtained by dividing the net profit/loss during the period of study by number of employees. The table 10 shows that the net profit/loss per employee ratio was positive only in (Rs.0.08 lac which was very low) 2000-01 and (Rs.5.05 lac) 2002-03 but in remaining years of the study period, it was negative. The figures in the table indicate that the Corporation had generated profits during the years 2000-01 and 2002-03 but incurred losses in all the remaining years. It is observed that the Corporation was incurring losses continuously from 2003-04 to 2012-13. The PSWC has shown the net losses may be due to rise in the expenses, under utilization of warehousing facilities, inefficiency of management and deficit from paddy $\&$ wheat procurement. It registered the negative compound growth rate and negative mean value during the study period. The negative ratio values indicated the lower employee productivity.

\section{TABLE 10- NET PROFIT/LOSS PER EMPLOYEE}

(Rs. in lac)

\begin{tabular}{|c|c|}
\hline Year & Net profit/loss per employee \\
\hline $2000-01$ & 0.08 \\
\hline $2001-02$ & -6.31 \\
\hline $2002-03$ & 5.05 \\
\hline $2003-04$ & -1.03 \\
\hline $2004-05$ & -2.41 \\
\hline $2005-06$ & -3.31 \\
\hline $2006-07$ & -4.62 \\
\hline $2007-08$ & -5.33 \\
\hline $2008-09$ & -2.14 \\
\hline $2009-10$ & -3.75 \\
\hline $2010-11$ & -6.40 \\
\hline $2011-12$ & -13.66 \\
\hline $2012-13$ & -17.08 \\
\hline MEAN & $\mathbf{- 4 . 6 8}$ \\
\hline CGR & -ive \\
\hline
\end{tabular}

(Source: Calculated from annual reports and the record of salary section of account branch of PSWC for the period 2000-01 to 2012-13) 


\section{Conclusion}

The productivity of PSWC has been analyzed on the basis of warehouse productivity and employee productivity. It was found that the average utilization per warehouse was less than the average storage capacity per warehouse in all the years because the average storage capacity of each warehouse of the PSWC was not fully utilized by the depositors and remained vacant over the study period. The PSWC earned more income than expenses per warehouse in 2000-01, 2002-03, 2003-04, 2004-05 and 2005-06 which showed that each warehouse of the Corporation was efficient in controlling its expenses but after 2005-06, income per warehouse was less than expenses per warehouse which indicated the inefficiency of the Corporation's warehouses in controlling the expenses. The net profit/loss per warehouse ratio was positive only in (Rs.1.46 lac which was low) 2000-01 and (Rs.77.36 lac) 2002-03 but in remaining years of the study period, it was negative may be due to rise in the expenses, under utilization of warehousing facilities and deficit from paddy \& wheat procurement.

It was also found that the quantity of paddy procured by each employee was more than the quantity of wheat procured by each employee of the Corporation from 2001-02 to 2011-12. The income per employee was more than the expenses per employee in the years 2000-01, 2002-03, 2003-04, 2004-05 and 2005-06 which represents that the Corporation's workforce was able in earning more income than expenses in these years. On the other hand, after 2005-06, the income per employee was less than the expenses per employee which showed the inability of the employees of the Corporation in controlling expenses. The results also show that the Corporation was incurring losses continuously from 2003-04 to 2012-13.

The study suggest that the PSWC should also store the other notified commodities like cement, steel, cotton textiles, leather, rubber, rubber products, fertilizers etc. alongwith the food grains for utilizing the vacant storage capacity of warehouses. The PSWC has needed to increase warehouse and employee productivity by controlling the expenses and increasing the income. The study further suggest that training/orientation programmes should be conducted at regular intervals to make the employees skilled, effecive and productive.

[1] Annual reports of PSWC from 2000-01 to 2009-10.

[2] Atmanand (1997), Productivity and Management of State Level Public Enterprises, Part- 2, Mittal Publications, New Delhi.

[3] Grewal, Ramanjeet Kaur (1990), Organization and Working of the Haryana Warehousing Corporation, PhD thesis submitted to Punjab University, Chandigarh.

[4] Kumari, Harish (2003), Productivity of Banks:- A Comparison of Public Sector and Private Sector Banks in India, PhD thesis submitted to Punjabi University, Patiala.

[5] Kaur, Manvir (2011), Performance Appraisal of Milk Cooperatives: A Comparative Study of MILKFED and HDDCF, M.Phil dissertation submitted to Punjabi University, Patiala.

[6] Kainth, G.S. (1982), Food grain Procurement Policy in Punjab, Margin, Vol.14, No.3, April.

[7] Madalgi, S.S. (1961), Warehousing Development in India, The Indian Journal of Agricultural Economy, pp. 57-62.

[8] Mishra, Pasanna Kumar and Misra, Devi Prasad (2005), Role of Warehouses in Indian Economy, Kalpaz Publications, New Delhi.

[9] Patil, Mallikarjunagouda S. (2007), Performance of Warehousing in Karnataka-A Comparative Analysis, M.B.A. dissertation submitted to University of Agricultural Sciences, Dharwad

[10] Prokopenko, Joseph (1987), Productivity Management, International Labour Office, Geneva, pp. 3 and 5-6.

[11] Statistical Abstract of Punjab 2010-11 and 2011-12.

[12] www.pswcorp.com

[13] pswc.in 